\title{
Reinforced Transparencies for Aerospace Application - Case Description
}

\author{
Melis De Bruyn Neto ${ }^{1}$ Rita de Cássia Mendonça Sales,2, Koshun Iha1, José Atílio Fritz Fidel Rocco
}

\begin{abstract}
This paper describes the polycarbonate acrylic laminated development that can be applied in aeronautics and aerospace transparencies. The case studied is a laminated double-curved transparency (bubble form) used in an observation side window of a military aircraft. Side windows need strength and specific characteristics, similar to windshields, allowing the perfect visualization and image capture. Laminated transparencies composed by different materials have better qualities than the monolithic ones. This kind of transparency can offer high mechanical and chemical resistance, high transparency, no fragmentation and easy maintenance or recovery. A significant amount of information about materials and processes was jointed in order to build the reinforced transparency and validate this study. The final results were analyzed based on two points of view: mechanic resistance and, especially, optical quality.
\end{abstract}

KEYWORDS: Transparency, Laminated polycarbonate, Acrylic, Window.

\section{INTRODUCTION}

Whenever it is necessary to see or capture images through a protective barrier, it arises the need to define it and build it as effectively and efficiently as possible. The problem that comes from this observation is to measure all the variables that can influence the requirements and, mostly important, to define the materials that can be used, as well as the methods and processes that will lead to the manufacture of a quality product. The materials chosen, suitable for the construction of reinforced transparencies for aerospace industry, as windshields, must to be taken into account, as well as all loads they are subjected to, including structural terms, mechanical and thermal loads (Fam and Rizkalla 2006). In addition, superior optical characteristics are also essential (Fixler 1977).

The modern engineering and architecture "design" requires glazing materials that offer high levels of safety and high-performance mechanical properties. These properties include: ballistic resistance; wind loads; explosion; and physical attacks resistance. In some applications, noise level reduction, solar radiation resistance, and thermal barrier behavior are also desirable. The laminated glazing is the union of multiple layers of various materials such as glass, polymeric films, resins, and flexible sheets of transparent polymers (polycarbonate and/or acrylic), usually applied to obtain complex geometric shapes (Fixler 1977; Smith et al. 1996).

It is necessary a prior knowledge of the physicochemical properties of the engineering materials to make the right choice for each application. To the right choice, it is necessary to know the load or the effort to which the transparency must resist and the kind of effort that will be neutralized by the transparent barrier. However, it should be clear that there will always be an effort

1.Departamento de Ciência e Tecnologia Aeroespacial - Instituto Tecnológico de Aeronáutica - Divisão de Ciências Fundamentais - São José dos Campos/SP - Brazi . 2.Centro Estadual de Educação Tecnológica Paula Souza - Faculdade de Tecnologia de São José dos Campos - Prof. Jessen Vidal - São José dos Campos/SP - Brazil. Author for correspondence: Rita de Cássia Mendonça Sales| Centro Estadual de Educação Tecnológica Paula Souza - Faculdade de Tecnologia de São José dos Campos - Prof. Jessen Vidal | Avenida Cesare Mansueto Giulio Lattes, 1.350 - Eugênio de Melo | CEP: 12.247-014 - São José dos Campos/SP - Brazil | Email: rita.sales@fatec.sp.gov.br Received: 11/19/2015 | Accepted: 02/04/2016 
that can overcome the barrier, because there is no definitive mechanical barrier. Thus, the barrier will be "strengthened" until reaching the desired resistance and including a safety factor.

Besides the mechanical strength, transparent barriers must have optical quality, being able to see or capture images by means of high light transmission level, with a minimum deviation or absorption, until the images reach the observer's eye or the image capture device.

Reinforced transparencies are not only intended to prevent a mechanical failure, but to perform with maximum efficiency and preferably not releasing fragments that reach whom or what will be protected by the transparent barrier. The objective of this study was to describe the information needed to design and to construct a reinforced transparency for aerospace application made with polymeric materials, which is part of the "observation window" of a military patrol aircraft.

\section{MATERIALS AND METHODS MATERIALS CHOICE}

The materials chosen for the observation window were based on MIL-PRF-5425E (1998) and MIL-P-46144C (1986). The chosen structural materials, in sheet form, were: acrylic or polymethylmethacrylate - PMMA (ASTM D4802-02) (Modified “cast” acrylic ACRYLITE® 249, CYRO Ind, USA); polycarbonate - PC (Fox and Christopher 1962; LeGrant and Bendler 2000) (LEXAN® 9034, GE-Plastics, USA); and, for bonding, in film form, polyurethane - PU (KRYSTALFLEX®PE399, Huntsman, USA), which is the material that allows a good adhesion between acrylic and polycarbonate.

The following sequence was used to prepare the specimens: two outer layers with $3.18 \mathrm{~mm}$ thickness of acrylic (PMMA); a central PC layer with $6.35 \mathrm{~mm}$ thickness; and between acrylic and PC layers, two aliphatic PU layers with $1.27 \mathrm{~mm}$ thickness were inserted. In other words, the final composition was: $\mathrm{PMMA}+\mathrm{PU}+\mathrm{PC}+\mathrm{PU}+\mathrm{PMMA}$ (Fig. 1).

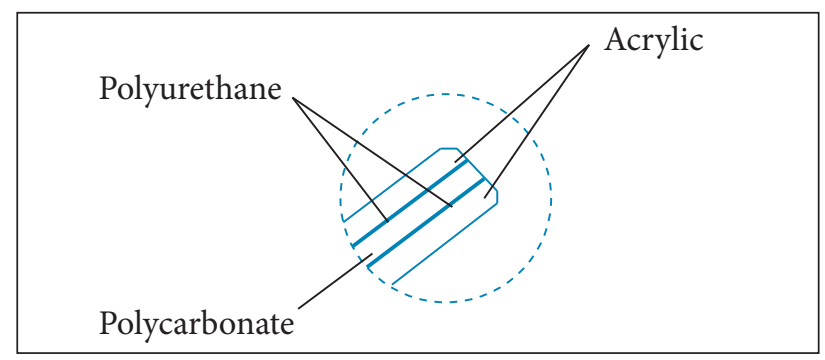

Figure 1. Materials sequence in specimens section.

\section{TEMPERATURE RESISTANCE TEST}

Two samples with nominal size $(20 \times 10 \mathrm{~cm})$ were prepared and laminated in the same way of the shearing test samples. The samples were submitted to $100{ }^{\circ} \mathrm{C}$ for $50 \mathrm{~min}$, using a circulating air oven (Kamp).

\section{SPECIMENS PREPARATION}

All the raw material plates were cut into dimensions much larger than the finished parts, using a circular saw. After this process, the plates were dehumidified at $100{ }^{\circ} \mathrm{C}$, during $6 \mathrm{~h}$ in an air circulating oven.

The dehumidified materials were laminated in the sequence previously defined. A vacuum bag was prepared around the laminated (all the bagging materials are from Airtech ${ }^{\circledR}$, USA; vacuum film and sealant tape). The set, formed by the laminate and the vacuum bag, was placed in an autoclave (FERLEX®, Brazil) to be bonded. To ensure the bonding material, the set formed by the laminate and the vacuum bag was heat-treated to $120^{\circ} \mathrm{C}$ for $2 \mathrm{~h}$ at a $2{ }^{\circ} \mathrm{C} / \mathrm{min}$ heating rate and pressured at $0.7 \mathrm{MPa}$ inside the autoclave. The temperature and pressure were maintained during $3 \mathrm{~h}$; then, it was cooled until the ambient temperature was reached. At the end, the pressure was released and the cycle, finished.

\section{THERMOFORMING PROCESS}

After autoclave process, the set was placed on a tool designed for the observation window manufacture. The tooling (Fig. 2) was heated to $180{ }^{\circ} \mathrm{C}$ at a $6{ }^{\circ} \mathrm{C} / \mathrm{min}$ heating rate. After the laminate reached the melting point, it was blown at a pressure of $0.14 \mathrm{MPa}$ to achieve its definitive new shape. The specimen was then cooled at $2{ }^{\circ} \mathrm{C} / \mathrm{min}$.

The part trimming was performed in a conventional manner using bandsaw and sander. The polishing was done using fine finishing hand tools and then through sandpapers and finer abrasives, until it reached the desired polishing. The specimen, properly polished, was placed against a reticule grid to check possible optical distortions.

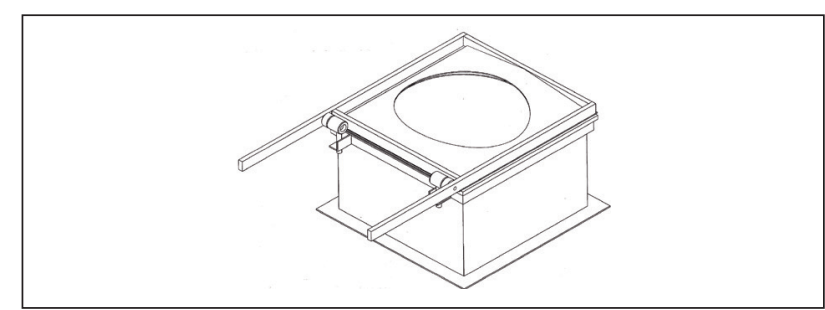

Figure 2. Thermoforming tool. 


\section{SHEARING TESTS IN PLANE}

Six samples with nominal size $(4.0 \times 5.0 \mathrm{~cm}$; section area: $20 \mathrm{~cm}^{2}$ ) were prepared using the following materials: an acrylic sheet, with $3.18 \mathrm{~mm}$ thickness, adhered to a PC sheet, with $6.35 \mathrm{~mm}$ thickness. For the sheets adhesion, it was used an aliphatic PU crystal adhesive film with $1.27 \mathrm{~mm}$ thickness.

The samples were laminated in the same way of the observation window. They were tested after $48 \mathrm{~h}$ of stabilization. The shearing test was performed in plane (Fig. 3) using MIL-P-25690B (1995) as general references. It was used an electromechanical testing machine for tension and compression Tinus Olsen brand, model $\mathrm{H} 100 \mathrm{KS}$, with maximum capacity of $100 \mathrm{kN}$. The test speeds were 3 and $5 \mathrm{~mm} / \mathrm{min}$.

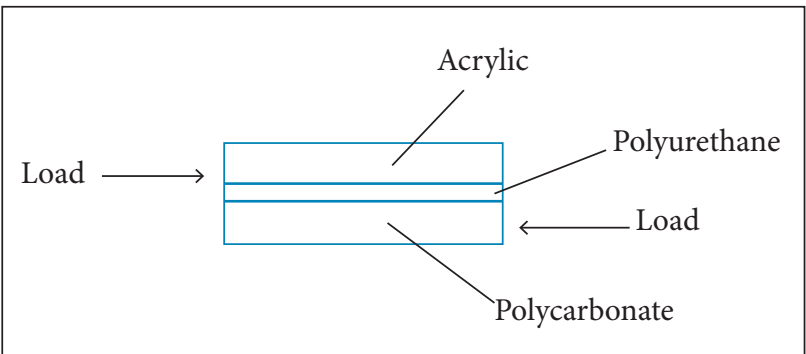

Figure 3. Schematic diagram of load applied in samples during the shearing tests in plane.

\section{RESULTS AND DISCUSSION MATERIALS CHOICE}

Nowadays, most of civil and military aircraft windows are made with acrylic (PMMA) due to its transparency, availability, strength and ease maintenance, fulfilling all the aviation requirements and standards (Blass 1985; LaPluma and Bridenbaugh 1988). This material also meets the requirements for external surfaces of reinforced transparency. However, in case of violent impact, it can shatter, causing sudden aircraft depressurization. To satisfy the high impact strength requirement, the best polymer is PC, already used in military fighter aircraft canopies (Wiser 1971). Both materials have high light transmission levels and they are thermoformable. To connect these two materials, the aliphatic PU films (Plepis 1991; Vilar 1991) can be used, providing the adhesion between layers. Table 1 shows the properties of the chosen materials for the manufacture of aircraft observation window.

After materials selection, it was carried out a temperature resistance test to verify the laminate behavior at $100{ }^{\circ} \mathrm{C}$.
Table 1. Acrylic and polycarbonate mechanical properties.

\begin{tabular}{|c|c|c|}
\hline Material & $\begin{array}{c}\text { Modified "Cast" } \\
\text { Acrylic }\end{array}$ & Polycarbonate \\
\hline $\begin{array}{c}\text { Standard } \\
\text { Commercial } \\
\text { type }\end{array}$ & MIL-PRF-5425E 1998 & MIL-P-46144C 1986 \\
\hline $\begin{array}{c}\text { Provider } \\
\text { Poisson's } \\
\text { ratio }\end{array}$ & CYRO Ind, USA & GE-Plastics, USA \\
\hline $\begin{array}{c}\text { Tensile } \\
\text { strength }\end{array}$ & 0.35 & 0.37 \\
\hline $\begin{array}{c}\text { Maximum } \\
\text { elongation }\end{array}$ & $80.3 \mathrm{MPa}$ & $65.5 \mathrm{MPa}$ \\
\hline $\begin{array}{c}\text { Tensile } \\
\text { Modulus }\end{array}$ & $2.76 \mathrm{GPa}$ & $110.0 \%$ \\
\hline $\begin{array}{c}\text { Compressive } \\
\text { strength }\end{array}$ & $124.1 \mathrm{MPa}$ & $2.39 \mathrm{GPa}$ \\
\hline $\begin{array}{c}\text { Flexural } \\
\text { strength }\end{array}$ & $113.76 \mathrm{MPa}$ & $86.18 \mathrm{MPa}$ \\
\hline $\begin{array}{c}\text { Shear } \\
\text { strength } \\
\text { (ultimate) }\end{array}$ & $62.05 \mathrm{MPa}$ & $68.95 \mathrm{MPa}$ \\
\hline $\begin{array}{c}\text { Izod impact } \\
\text { (notched) }\end{array}$ & 21.35 & $640.5-854$ \\
\hline
\end{tabular}

There was no appearance of undesirable bubbles, yellowing, delamination or any other conduct that could compromise the functions of the laminate or its general appearance. It was also verified that the temperature would not compromise the good light transmission without distortion or deformation.

\section{SHAPE DETERMINATION}

The final shape of the transparency is better defined by the obtaining process than by a geometry defined through engineering software (Fig. 4). The method used to obtain the transparency form was the thermoforming by blowing compressed air (Blass 1985), since it allows the material to expand freely until the desired format is obtained.

The expansion process by free blowing determines the shape and cooperates with the optical quality, avoiding deformities, and it does not cause undesirable distortions in contact with the tool - they are visible only at the edges of transparency. The result by thermoforming is an elliptical paraboloid shape (Fig. 5), caused by laminated thinning (more in the center than in the edges), because of area increasing and thickness loss. 


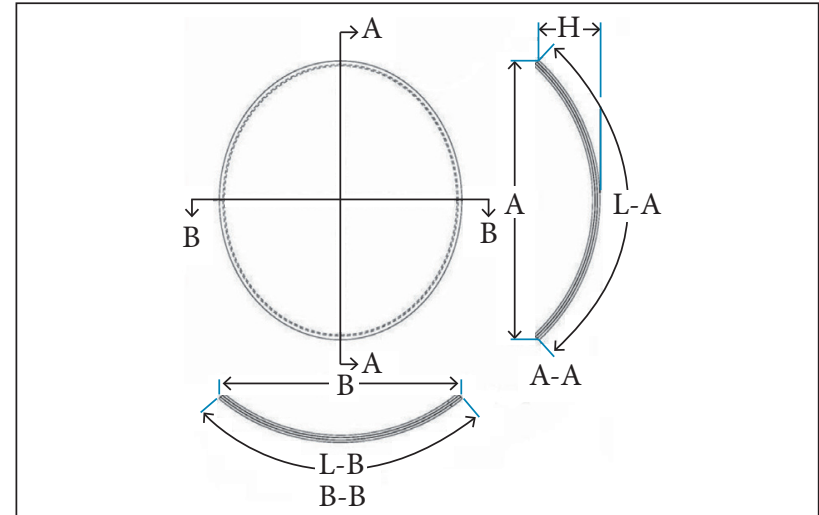

Figure 4. Orthogonal views and transparency section. A-A: Height; B-B: Width; L-A: Vertical vision angle; L-B: Horizontal vision angle; $\mathrm{H}$ : Depth.

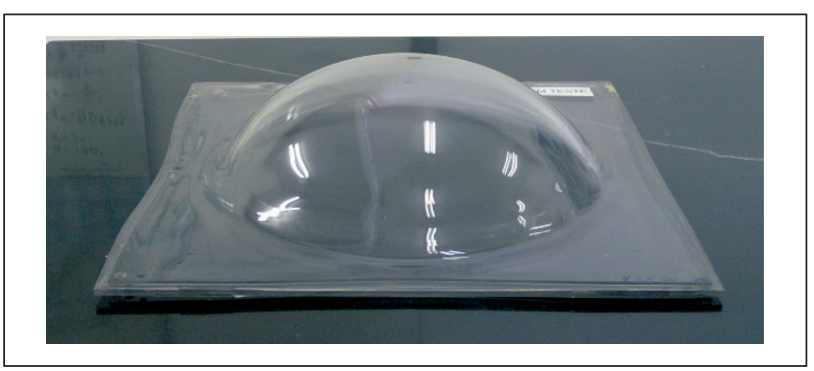

Figure 5. Laminated after thermoforming made with an appropriate tool.

\section{OPTICAL DISTORTIONS}

Samples submitted for verification did not have relevant distortions, detected by the human eye, which could compromise the good appearance of the grid images captured through the transparence (Fig. 6). However, it was detected the presence of a slight optical power due to thickness variation at the center of the part, resulting from thinning, occurred during the thermoforming process, which creates a kind of diverging lenses. The contact with the thermoforming tool produces contact marks that are manifested in the form of distortion of the edge part; however, these distortions do not affect the results, when transparency is in use, since it does not become apparent because this region is covered by the transparency frame.

The optical distortions verification (Fixler 1977) is an important parameter in reinforced transparencies (Pardini and Peres 1996). The reinforced transparency, besides being considered a barrier to prevent an effort to continue, should allow observing or capturing images through it with the best possible quality, not adding deviations image distortions, retain the light wavelength or filter visible spectrum.

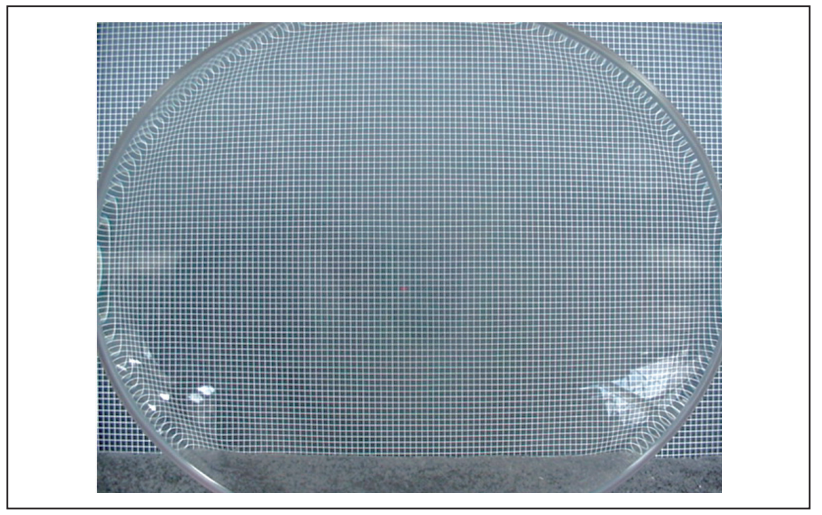

Figure 6. Transparency view without distortions in the central area.

All the images captured during the transparencies flight test had an excellent clarity and no visible distortions, which confirmed the prior results obtained with the grid.

\section{SHEARING RESULTS IN PLANE}

Aircraft side windows have a significant temperature differential between inner and outer layer, as much higher as the aircraft flying altitude. The internal temperature is usually around $20^{\circ} \mathrm{C}$, and the outer temperature can be less than $-54^{\circ} \mathrm{C}$, so the dimensional variation between layers produces high big shear forces that must be compensated by the polyurethane layer elasticity. In this case, the PU adhesion between acrylic and/or polycarbonate must be verified. The shear test indicates the degree of adhesion acquired by the laminated.

Each trial lasted until a little over $2 \mathrm{~min}$, since the total displacement was around $6 \mathrm{~mm}$. Tables 2 and 3 contain the results obtained in the shear test.

The test speed of $3 \mathrm{~mm} / \mathrm{min}$ was appropriate, according to the behavior observed, which does not present a premature rupture and produces a clear "load $\times$ deflection" curve. The standard deviation in general demonstrates a short range of values, or more reliability in the results obtained. The test speed of $5 \mathrm{~mm} / \mathrm{min}$ does not produce results with small variation, since the values obtained were two or three times higher than the values obtained with test speed of $3 \mathrm{~mm} / \mathrm{min}$.

The maximum shear stress average demonstrates a satisfactory adhesion degree between layers in both speed tests and was greater than the expected.

A more detailed analysis of the displacement data between the sheets of acrylic and polycarbonate may provide an order of magnitude for the lengthening ability of the polyurethane adhesive, but the PU manufacturer (Huntsman, USA) indicates 
Table 2. Results obtained in the shear test at the speed of $3 \mathrm{~mm} / \mathrm{min}$.

\begin{tabular}{|c|c|c|c|c|}
\hline Sample & $\begin{array}{l}\text { Maximum load } \\
\text { [kgf] }\end{array}$ & $\begin{array}{c}\text { Breaking load } \\
\text { (kgf] }\end{array}$ & $\begin{array}{l}\text { Displacement } \\
\text { [mm] }\end{array}$ & $\begin{array}{c}\text { Shear stress } \\
{\left[\mathrm{kgf} / \mathrm{cm}^{2}\right]}\end{array}$ \\
\hline S1 & $1,010.2$ & 982.7 & 6.2 & 49.1 \\
\hline S3 & $1,034.3$ & 967.7 & 6.4 & 48.4 \\
\hline S5 & 972.8 & 896.7 & 6.3 & 44.8 \\
\hline Average & $1,005.8$ & 949.0 & 6.3 & 47.5 \\
\hline Standard deviation & 31.0 & 45.9 & 0.1 & 2.3 \\
\hline
\end{tabular}

Table 3. Results obtained in the shear test at the speed of $5 \mathrm{~mm} / \mathrm{min}$.

\begin{tabular}{|c|c|c|c|c|}
\hline Sample & $\begin{array}{c}\text { Maximum load } \\
\text { (kgf) }\end{array}$ & $\begin{array}{c}\text { Breaking load } \\
{[\mathrm{kgf}]}\end{array}$ & $\begin{array}{c}\text { Displacement } \\
\text { (mm) }\end{array}$ & $\begin{array}{c}\text { Shear stress } \\
{\left[\mathbf{k g f} / \mathrm{cm}^{2}\right]}\end{array}$ \\
\hline S2 & $1,059.2$ & $1,027.5$ & 6.2 & 51.4 \\
\hline S4 & 881.4 & 793.3 & 5.8 & 39.7 \\
\hline S6 & 951.1 & 913.7 & 5.7 & 45.7 \\
\hline Average & 963.9 & 911.5 & 5.9 & 45.6 \\
\hline Standard deviation & 89.6 & 117.1 & 0.3 & 5.9 \\
\hline
\end{tabular}

$500 \%$ of elongation at the KRYSTALFLEX ${ }^{\circledR}$ PE399 datasheet (Huntsman 2015).

All samples tested were broken or showed detachment from plastic layers. The S2 had supported the major load, and S4, the minor one. Figure 7 shows a typical curve of "load $\times$ deflection" generated by $\mathrm{S} 2$ test.

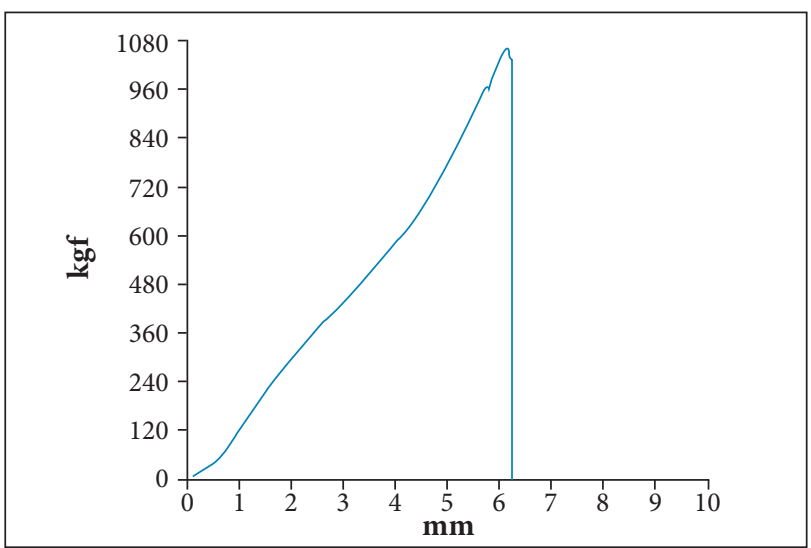

Figure 7. Curve "load $\times$ deflection" of the S2.

\section{CONCLUSIONS}

The objective was achieved by implementing the proposed road map, which was to organize some of the information needed to design and to construct a reinforced transparency for an aerospace application, which is part of the "observation window" of a military patrol aircraft, as well as to validate such information through the construction of the transparency and analysis of the results.

The combination of the techniques used and the layers union in an appropriate and sequential manner was essential for the construction of transparency, which was successfully completed. Any failure would not allow the following step.

The optical results allow to state that the material choices were appropriate, especially on the composition and position of them. The acrylic usage on the internal and external faces of transparency had ensured the necessary optical quality. The fabrication process chosen, by the free expanding thermoforming, guaranteed a regular format of the visible area because there were no contacts with any tool.

All samples presented a satisfactory adhesion degree between layers during the shearing tests in plane. The parameters of speed test were greater than the expected, but this did not affect the results; the samples showed mechanical resistance parameters required by the aeronautical industry. Therefore, it was possible to demonstrate the technological knowledge necessary for the development and manufacture of reinforced aerospace transparencies for this type of application. 


\section{REFERENCES}

Blass A (1985) Processamento de polímeros. Florianópolis: UFSC.

Fam A, Rizkalla S (2006) Structural performance of laminated and unlaminated tempered glass under monotonic transverse loading. Construct Build Mater 20(9):761-768. doi: 10.1016/ j.conbuildmat.2005.01.051

Fixler SZ (1977) Thermsstructural and material considerations in the design of the F-14 Aircraft Transparencies. J Aircraft, 14[3]:257264.

Fox DW, Christopher WF (1962) Polycarbonates. New York: Reinhold Publishing Corporation.

Huntsman (2015) KRYSTALFLEX® PE399 data sheet on line. [accessed 2015 Oct 15]. http://www.huntsman.com/polyurethanes

LaPluma PT, Bridenbaugh JC (1988) Specifications and measurement procedures for aircraft transparencies. Wright-Patterson AFB, $\mathrm{OH}$ : Armstrong Aerospace Medical Research Laboratory.
LeGrant DG, Bendler JT (2000) Handbook of polycarbonate science and technology. New York: Marcel Dekker.

Pardini LC, Peres RJC (1996) Tecnologia de fabricação de préimpregnados para compósitos estruturais utilizados na indústria aeronáutica. Polímeros 6(2):32-42.

Plepis AMD (1991) Caracterização térmica e viscoelástica de resinas poliuretanas derivadas do óleo de mamona (Master's thesis]. São Paulo: Universidade de São Paulo.

Smith FC, Moloney LD, Matthews FL, Hodges J (1996) Fabrication of woven carbon fibre/polycarbonate repair patches. Compos Appl Sci Manuf 27(11):1089-1095. doi: 10.1016/1359-835X[96)00070-X

Vilar WD (1991) Química e tecnologia dos poliuretanos. 2nd ed. Rio de Janeiro: Vilar Consultoria Técnica Ltda.

Wiser GL [1971] Transparency applications of polycarbonates. Aircraft Eng 43(8):18-20. doi: 10.1108/eb034797 